\title{
Incidence of Aspergillus in Grapes Intended To Juice and Wine Prodution
}

\author{
Bruna Dachery (I), Sheila Canossa (I), Emilli Keller Bol (I), Débora \\ Senger (I), Flávio Veras (I), Vitor Manfroi (I), Juliane welke (I) \\ (I) UFRGS - Universidade Federal do Rio Grande do Sul (Avenida Bento Gonçalves, 9500,CEP \\ 91501-970 Porto Alegre, RS)
}

\section{Resumo}

Aspergillus species belonging to the section Nigri are known as the foremost fungi responsable for ochratoxin A (OTA) contamination of grapes and their products. A. carbonarius has been reported as the main cause for high level of OTA in grapes. OTA is a mycotoxin with nephrotoxic, carcinogenic, immunotoxic, genotoxic and teratogenic effects. This toxin was classified as a possible human carcinogenic by International Agency for Research on Cancer. Apart from cereals, grapes, juice and wines are the commodities with highest incidence of OTA contamination. The presence of OTA in juice and wine occurs due to fungal contamination of the grapes during the cultive, transport and storage. The objective of this work was to evaluate the incidence of Aspergillus in grapes of varieties Cabernet Sauvignon, Moscato e Concord intended for the production of juice and wine. The grapes used in this work were collected in february of 2014 at a winery of Serra Gaúcha region of Rio Grande do Sul state, Brasil. Grape berries were separated from bunches and were surface-sterilised by dipping them into a solution of sodium hypochlorite $(0.1 \%)$. Berries were placed in plates containing potato dextrose agar. Black Aspergillus were isolated on Czapek Yeast extract Agar and Malt Extract Agar for identification at species level. Plates were maintained at $25^{\circ} \mathrm{C}$ for 7 days. The following features were used for fungi identification: the growth diameter of the colonies; the characteristics and color of the mycelium; the production of pigments and exudates; the characteristics of the

\footnotetext{
Referência:

Bruna Dachery, Sheila Canossa, Emilli Keller Bol, Débora Senger, Flávio Veras, Vitor Manfroi, Juliane welke.Incidence of Aspergillus in Grapes Intended To Juice and Wine Prodution. In: Anais do 12ㅇ Congresso Latinoamericano de Microbiologia e Higiene de Alimentos - MICROAL 2014 [= Blucher Food Science Proceedings, num.1, vol.1]. São Paulo: Editora Blucher, 2014. 
conidiophores and conidia. The potential toxigenic of Aspergillus strains were determined through chloroform extraction and application of organic extract in thin layer chromatography with charge coupled device.

Seventeen fungi belonging to the Aspergillus genus were isolated from grapes. Cabernet Sauvignon and Concord showed the highest incidence of ochratoxigenic Aspergillus with two strains OTA producing from each grape variety. In Moscato grapes only one strain with capacity to produce this toxin was detected. The presence of OTA producing strains in grapes may result in the occurrence of this toxin in juice and wine, then depending to the levels of the mycotoxin found in products, the population may be exposed to the risk related to the toxic effects of OTA.

Palavras-Chave: mycotoxin, ochratoxin A, A. carbonarius Agência de Fomento: CNPq, FAPERGS and CAPES 